\title{
Three extreme storms over Europe in December 1999
}

\author{
Article \\ Published Version
}

Ulbrich, U., Fink, A. H., Klawa, M. and Pinto, J. G. (2001)

Three extreme storms over Europe in December 1999.

Weather, 56 (3). pp. 70-80. ISSN 0043-1656 doi:

https://doi.org/10.1002/j.1477-8696.2001.tb06540.x Available at https://centaur.reading.ac.uk/32834/

It is advisable to refer to the publisher's version if you intend to cite from the work. See Guidance on citing.

Published version at: http://dx.doi.org/10.1002/j.1477-8696.2001.tb06540.x

To link to this article DOI: http://dx.doi.org/10.1002/j.1477-8696.2001.tb06540.x

Publisher: Wiley

All outputs in CentAUR are protected by Intellectual Property Rights law, including copyright law. Copyright and IPR is retained by the creators or other copyright holders. Terms and conditions for use of this material are defined in the End User Agreement.

\section{www.reading.ac.uk/centaur}

\section{CentAUR}

Central Archive at the University of Reading

Reading's research outputs online 


\title{
Three extreme storms over Europe in December 1999
}

\author{
U. Ulbrich, A. H. Fink, M. Klawa and J. G. Pinto \\ Institut für Geophysik und Meteorologie der Universität zu Köln, Germany
}

In December 1999, central Europe was hit by three violent storms, which claimed more than 130 lives and caused about 13 billion Euros worth of total economic losses. The first of these storms hit Denmark and the northernmost part of Germany on 3 December 1999 (Fig. 1(a)). It was associated with a cyclone named Anatol by the German Weather Service
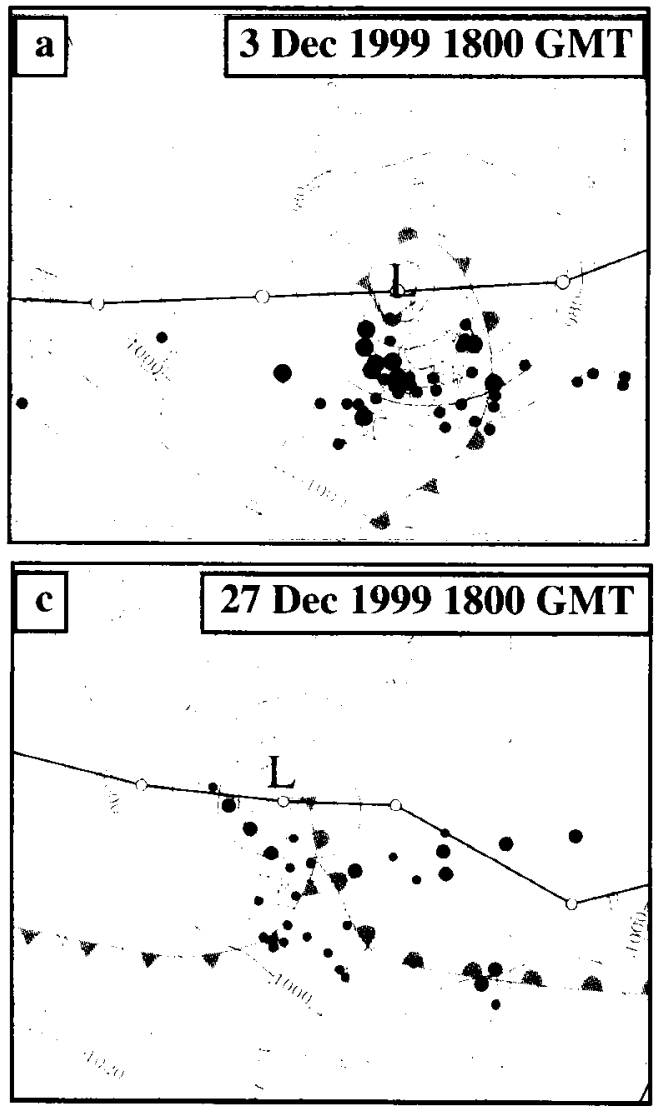

(DWD) (the DWD gives a name to each North Atlantic cyclone). At the Danish and German North Sea coast, gales of more than $50 \mathrm{~m} \mathrm{~s}^{-1}$ $(97 \mathrm{kn})$ and a record storm surge were observed. Extreme wind speeds also occurred in central and eastern Denmark, with gusts as strong as $43 \mathrm{~m} \mathrm{~s}^{1}(83 \mathrm{kn})$ in Copenhagen. According to a report issued by the Danish
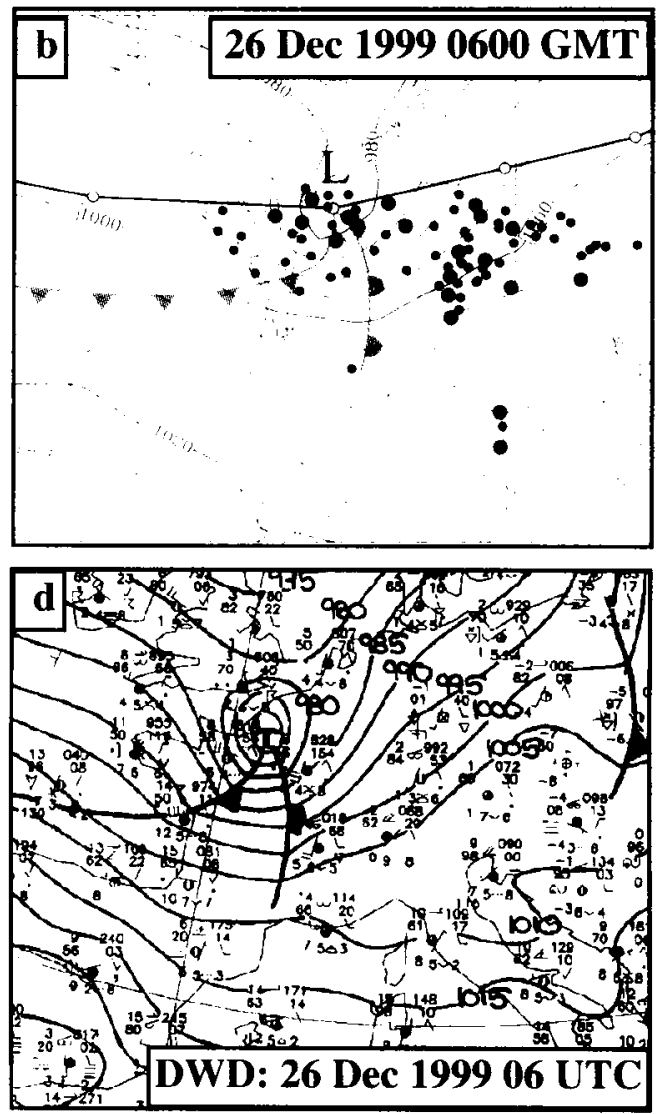

Fig. I ECMWF sea-level pressure analyses for (a) Anatol, (b) Lothar, and (c) Martin at the time of the most violent gusts. Contours are every 5 mbar. The small (large) black dots denote locations where the maximum gales within the storm period exceeded $63 \mathrm{kn}(80 \mathrm{kn})$. The 6-hourly storm positions are also indicated. (d) German Weather Service (DWD) operational manual surface analysis. The location of surface fronts is taken from the DWD analysis. 
Meteorological Institute (2000) this was the strongest storm of the century over Denmark.

The second storm event occurred on 26 December. It was caused by a low named Lothar, and left a trail of destruction from north-western France to southern Germany and Switzerland (Fig. 1(b)). Major damage was reported from the industrial belt around Paris and from well-known tourist sites, such as the church of Notre Dame in Paris and the park of Versailles. Gusts reaching wind speeds of almost $50 \mathrm{~m} \mathrm{~s}^{-1}(97 \mathrm{kn})$ were recorded at Paris/Orly Airport. In Germany and Switzerland the persistently violent gusts (over $41 \mathrm{~m} \mathrm{~s}^{-1}(80 \mathrm{kn})$ in Karlsruhe (Germany) and almost $37 \mathrm{~m} \mathrm{~s}^{-1}(72 \mathrm{kn}$ ) in Bern (Switzerland)) uprooted countless trees.

Only one day later, on 27 December 1999, gales associated with a low named Martin hit southern France and northern Spain (Fig. 1(c)). Again, extreme gusts over $40 \mathrm{~ms}^{-1}$ $(78 \mathrm{kn})$ occurred, this time in a belt extending from Bordeaux to Clermont-Ferrand, causing numerous road blockages and a widespread electricity breakdown which lasted for days.

In this paper, we will first give a description of the development of each storm. The subsequent discussion of the large-scale conditions in which the storms were embedded will reveal two common characteristics, namely a band of extremely high baroclinicity and high equivalent potential temperature. Evidence will be given that similar large-scale anomalies can also be identified for previous disastrous storm events over Europe. Finally, we will compare the observed anomalies with trends in a greenhouse gas scenario run of a general circulation model (GCM). Our paper will not touch the issue of the predictability of the storms and of the timeliness of the warnings issued by the different weather services.

Station data and operational ECMWF (European Centre for Medium-Range Weather Forcasts) analyses will be used to investigate the three recent storms, while NCEP (National Centers for Environmental Prediction) reanalyses are the data source for the historical storm events. The analysis/reanalysis data are expected to give a good representation of the observed large-scale conditions. We would like to point out that they fail, however, in repre- senting small-scale features such as the extreme pressure gradients associated with Lothar (cf. the operational manual surface analysis issued by the DWD (Fig. 1(d)) and the ECMWF numerical analysis (Fig. 1(b)). This is not solely due to the moderate $(60 \mathrm{~km})$ resolution of the ECMWF grid. Rather, several observed extreme surface pressure tendencies and winds have been rejected by the ECMWF's automatic data check and assimilation scheme (E. Anderson, personal communication), for example the observations at Rouen (France) at $0600 \mathrm{GMT}$ on 26 December 1999 (see Fig. 5). Without going into detail, one should recognise that operational analyses serve a high-quality forecast, which does not necessarily mean that observed extremes are incorporated.

Two parameters, the maximum Eady growth rate, $\sigma_{\mathrm{BI}}$, and the equivalent potential temperature, $\theta_{\mathrm{e}}$, are considered to study the large-scale atmospheric conditions in which the storms were embedded. The Eady growth rate (see Eady 1949; Lindzen and Farrell 1980; Hoskins and Valdes 1990) is a measure of baroclinicity, i.e. it quantifies the large-scale conditions for the potential growth of extratropical cyclones. It is defined as

$$
\sigma_{\mathrm{BI}}=0.31(f / N)|\partial \mathrm{v} / \partial z|
$$

where $f$ is the Coriolis parameter, $N$ is the Brunt-Väisälä frequency, and $\partial v / \partial z$ is the vertical wind shear. Since the gridded fields of $\sigma_{\mathrm{BI}}$ calculated from 3-day averages of the input parameters for the lower ( $850-700 \mathrm{mbar})$ and for the upper (500-300 mbar) troposphere proved to be similar in structure, we will show only the upper-level baroclinicity. The other considered parameter, $\theta_{\mathrm{e}}$ at $850 \mathrm{mbar}$, serves to quantify the combined effect of latent and sensible heat on the cyclones. It was computed on a 6-hourly basis according to a formula given in Bolton (1980).

The three recent storms are investigated using the high-resolution ECMWF operational analyses. When comparing the recent storms to historical storm events and estimating the extremeness of the associated large-scale conditions, we will use the lower-resolution NCEP reanalysis for 40 winters (1958/59-1997/98) as observational reference data. We performed an intercomparison of the considered large-scale 

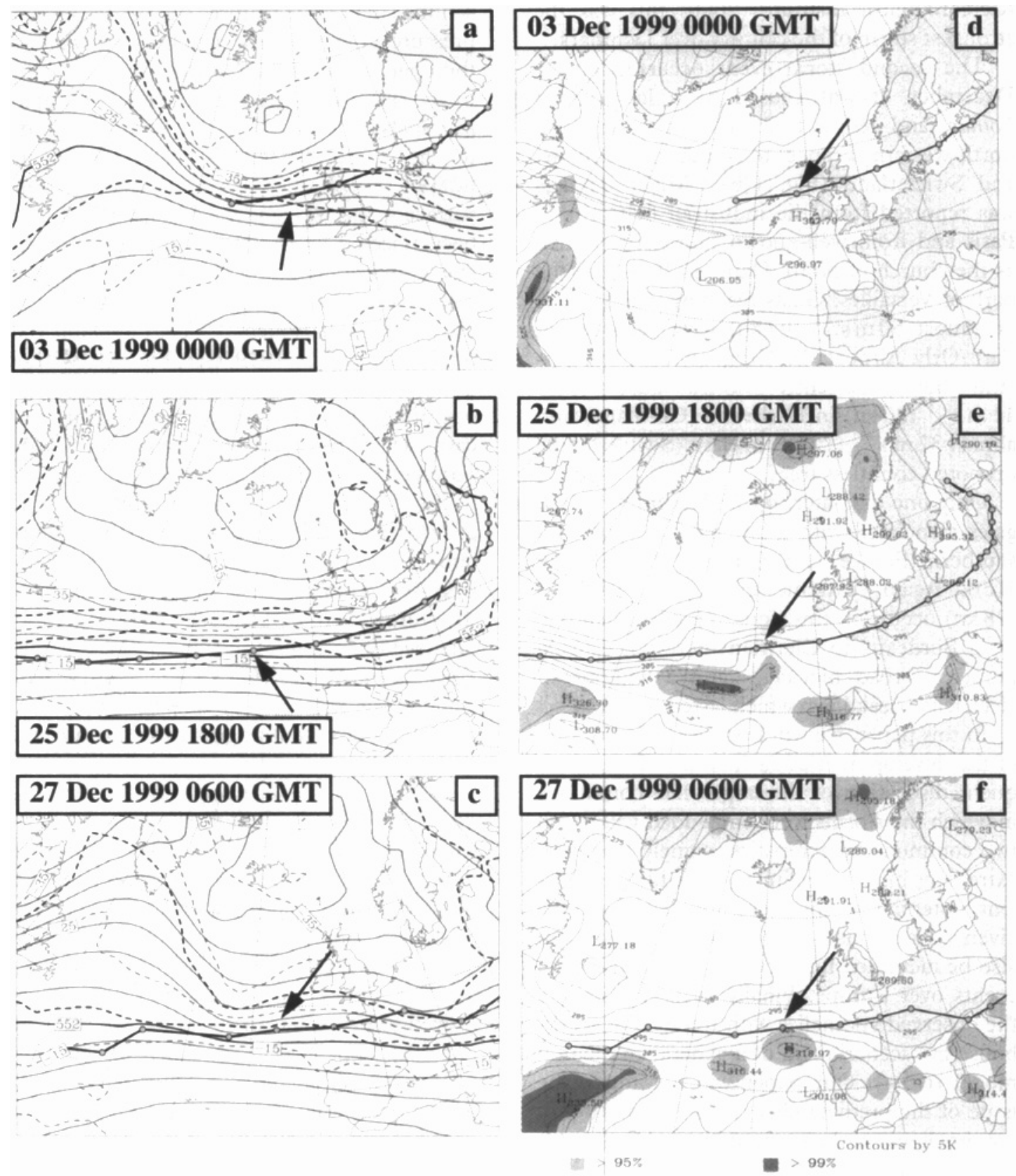

Fig. 2 Large-scale conditions associated with the storms: (a), (d) and (g) Anatol; (b), (e) and (h) Lothar; (c), (f) and (i) Martin. The left-hand column shows the 500 mbar geopotential height (solid lines, contour interval 8 dam) and temperature fields (broken lines, contour interval $5 \mathrm{degC}$ ), the middle column equivalent potential temperature (contour interval $5 \mathrm{~K}$ ) at $850 \mathrm{mbar}$, and the right-hand column (p.73) the 3-day averaged upper-level (300-500 mbar) maximum Eady growth rate (per day). Dates and associated cyclone locations (arrows) are indicated along with the cyclone track from 6-hourly positions. Grid points where local values exceed the 95 th and 99 th percentile are shaded.

quantities for storm events included in both ECMWF and NCEP data, and found no significant systematic differences between them.

\section{Anatol (2-4 December 1999)}

Before cyclone Anatol rapidly developed over the central North Atlantic south of Greenland 

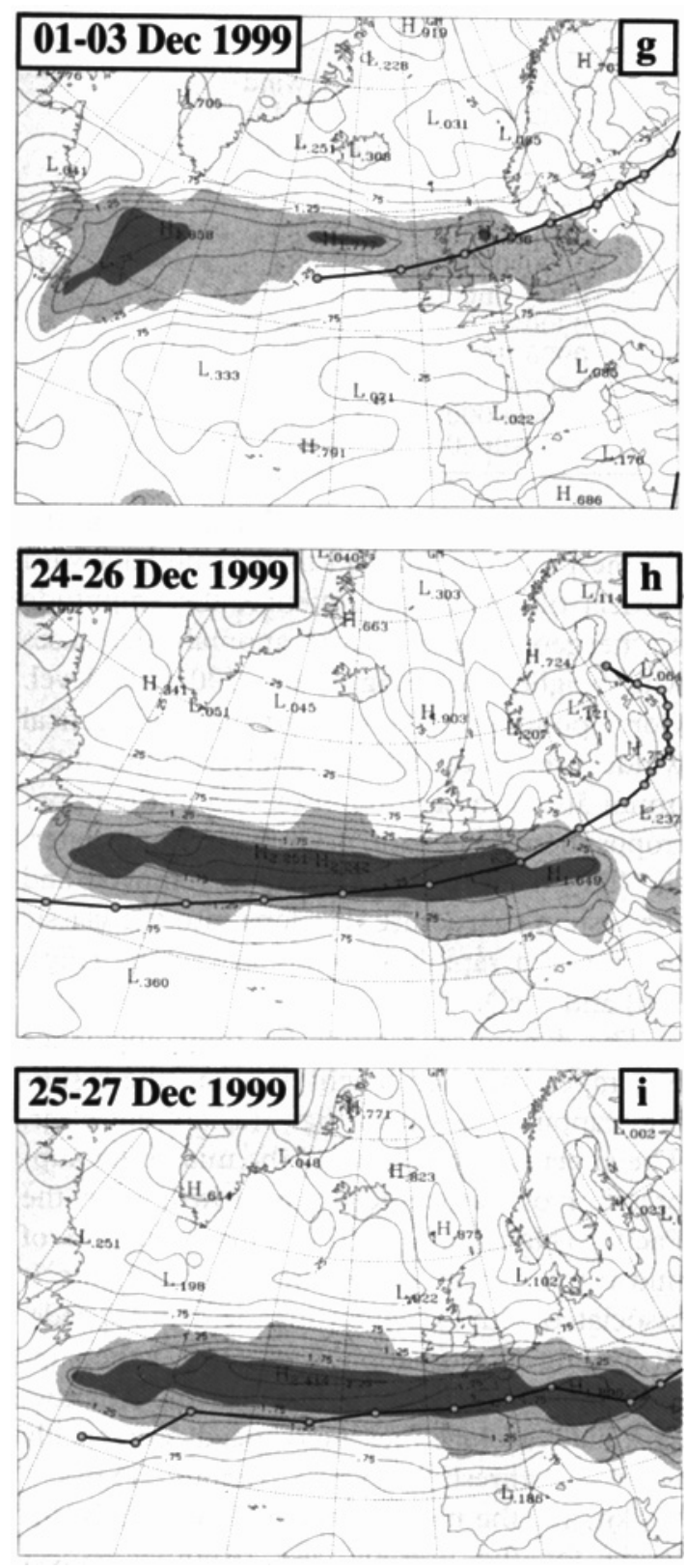

Fig. 2 Continued

two precursors could be identified. At the surface level, a small cyclonic vorticity perturbation moved north-eastward from Newfoundland, meeting an upper-air geopotential height disturbance approaching from Labrador (not shown). A closed isobar at the surface could be identified in the ECMWF analysis at 1800 GMT on 2 December 1999 when the system was located west of Ireland (for the cyclone paths see Fig. 2). The system moved on eastwards along the southern flank of a steering cold mid-tropospheric trough centred over Iceland (Fig. 2(a)). A tongue of warm air was located at the southern flank of the track (Fig. 2(d)). During its displacement within a highly baroclinic zone (Fig. 2(g)), Anatol deepened rapidly over the eastern North Atlantic. According to a ship observation, it reached a central pressure of about 990 mbar when it approached the British Isles at 0000 GMT on 3 December. Its rapid intensification continued over the subsequent 12 hours, fed by the large meridional temperature contrasts of the air integrated in the system. Extremely cold tropospheric air located in the area between Greenland and Norway (e.g. $-39^{\circ} \mathrm{C}$ at the $500 \mathrm{mbar}$ level over the Faeroe Islands at 0000 GMT on 3 December 1999) was advected to the North Sea in the wake of the system, while warm air prevailed in the south $\left(-20^{\circ} \mathrm{C}\right.$ over central England and Ireland at the same pressure level, see Fig. 2(a)). Later, Anatol's central pressure remained almost constant as it swept from the central North Sea (957 mbar at 1200 GMT) over the Danish North Sea coast (955 mbar at $1500 \mathrm{GMT}$ ) to Sweden (954 mbar at 2100 GMT). The lowest pressure was recorded at 1800 GMT (953 mbar) near the east coast of Jutland. Anatol filled slowly after crossing the Baltic Sea and reaching the Latvian coastline (970 mbar at 0600 GMT on 4 December 1999).

Figure 1(a) shows that the highest wind speeds occurred south of the cyclone core in a belt reaching from the German and southern Danish North Sea coast to Copenhagen and the Polish Baltic Sea coast (cf. also Table 1). Notably, gales exceeding $25 \mathrm{~m} \mathrm{~s}^{-1}(49 \mathrm{kn})$ were observed over Denmark during the 8hour period from 1400 to $2200 \mathrm{GMT}$, with the most violent winds between 1600 and 1800 GMT at the North Sea coast (cf. Sylt, Table 1). Wind direction and temperature recordings suggest that the peak gusts occurred with the passage of the cold front.

\section{Lothar (24-27 December 1999)}

The depression named Lothar initially developed on 24 December 0000 GMT off the North American east coast, at about $35^{\circ} \mathrm{N}$. It was 
Table 1 Maximum gust wind speed at selected lowland stations

\begin{tabular}{llcc}
\hline Date & $\begin{array}{l}\text { Station } \\
\text { (WMO No.) }\end{array}$ & $\begin{array}{c}\text { Time period } \\
(\mathrm{GMT})\end{array}$ & $\begin{array}{c}\text { Gust wind } \\
\text { speed } \\
\left(\mathrm{m} \mathrm{s}^{-1}\right) /(\mathrm{kn})\end{array}$ \\
\hline 3 Dec. 1999 & Sylt (10020) & $1500-1800$ & $51 / 99$ \\
3 Dec. 1999 & Kap Arkona (10091) & $2100-0000$ & $46 / 89$ \\
4 Dec. 1999 & Hel (12135) & $0000-0300$ & $43 / 84$ \\
26 Dec. 1999 & Alencon (07139) & $0300-0600$ & $46 / 89$ \\
26 Dec. 1999 & Schaffhausen (06620) & $0900-1200$ & $45 / 87$ \\
26 Dec. 1999 & Stuttgart (10738) & $0900-1200$ & $40 / 78$ \\
27 Dec. 1999 & Ile d'Yeu (07300) & $1800-2100$ & $45 / 87$ \\
27 Dec. 1999 & Clermont-Aulnat (07460) & $2100-0000$ & $44 / 86$ \\
28 Dec. 1999 & Calvi (07754) & $0300-0600$ & $44 / 86$ \\
\hline
\end{tabular}

apparently restricted to the lower troposphere, as we found no evidence for an associated upper-level disturbance. Subsequently, it entered the exceptionally strong baroclinic zone that had formed across the North Atlantic (Fig. 2(h)), where strong temperature gradients throughout the troposphere (Fig. 2(b)) led to a strong polar jet with core wind speeds of more than $100 \mathrm{~m} \mathrm{~s}^{-1}(194 \mathrm{kn})$ at $300 \mathrm{mbar}$ and temperatures of about $-53 \mathrm{C}$.

According to the classic concept of cyclone development, the high baroclinicity indicated by the strong vertical wind shear (Fig. 2(h)) is susceptible to the formation of an intense cyclone starting from the small initial disturbance. An upper-air anomaly would form, and the coupled upper- and lower-tropospheric disturbance would be expected to grow (type A development after Pettersen and Smebye (1971)). However, such growth did not occur until Lothar had crossed the Atlantic with a propagation speed of about $120 \mathrm{kmh}{ }^{1}$ $(65 \mathrm{kn})$ and reached Europe on 26 December 0000 GMT: The intense jet over the Atlantic remained almost unaltered during Lothar's passage over the Atlantic Ocean.

For a better understanding of the suppressed development of Lothar, it is instructive to compare the vertical structure of the disturbance shortly before and after its explosive growth. The non-growth phase is characterised by a geopotential height anomaly which is largest close to the surface (Fig. 3(a)). The lowlevel warm air advection upstream of the low (evident, for example, in Fig. 2(e)) results in a positive temperature anomaly. In contrast to the idealised situation of a growing baroclinic wave (e.g. Holton 1992, Fig. 6.6), however, the vertical trough axis and the axis of the warmest air coincide and there is no backward vertical tilt. As a consequence, the amplitude of the geopotential height anomaly decreases with height, vanishing at the $500 \mathrm{mbar}$ level. Correspondingly, the upward directed vertical winds given in the ECMWF analysis with a maximum at 700 mbar do not extend to the upper troposphere (Fig. 3(a)). Only six hours later, the 'lid on top of the system' is removed and the system's structure develops into the classic picture of a rapidly developing cyclone (Figs. 3(b) and 3(c)).

The dynamical reasons for the coincidence of temperature and height axis and the resulting 'capping' shown in Fig. 3(a) are not clear. The effect is reminiscent of the midwinter suppression of baroclinic wave growth over the Pacific (Nakamura 1992). This reduction of mid-tropospheric baroclinic wave activity is associated with extremely high jet wind speeds. According to Christoph et al. (1997) the suppression is usually not active over the Atlantic, as zonally averaged jet wind speeds are usually below a threshold value (about $45 \mathrm{~m} \mathrm{~s}^{-1}$ $(87 \mathrm{kn})$ for the monthly mean), but this is different for the present case. Another aspect might be that Lothar's wavelength was too small for significant baroclinic growth.

Lothar's rapid development started when an additional factor set in at the time the storm reached the jet's exit region at 0000 GMT on 26 December (Fig. 4). A strong divergence centre associated with upper-level diffluence was located between Brittany and Cornwall, north of the jet axis. It was already present at previous dates and thus was not generated by the approaching cyclone. Such areas of intense 

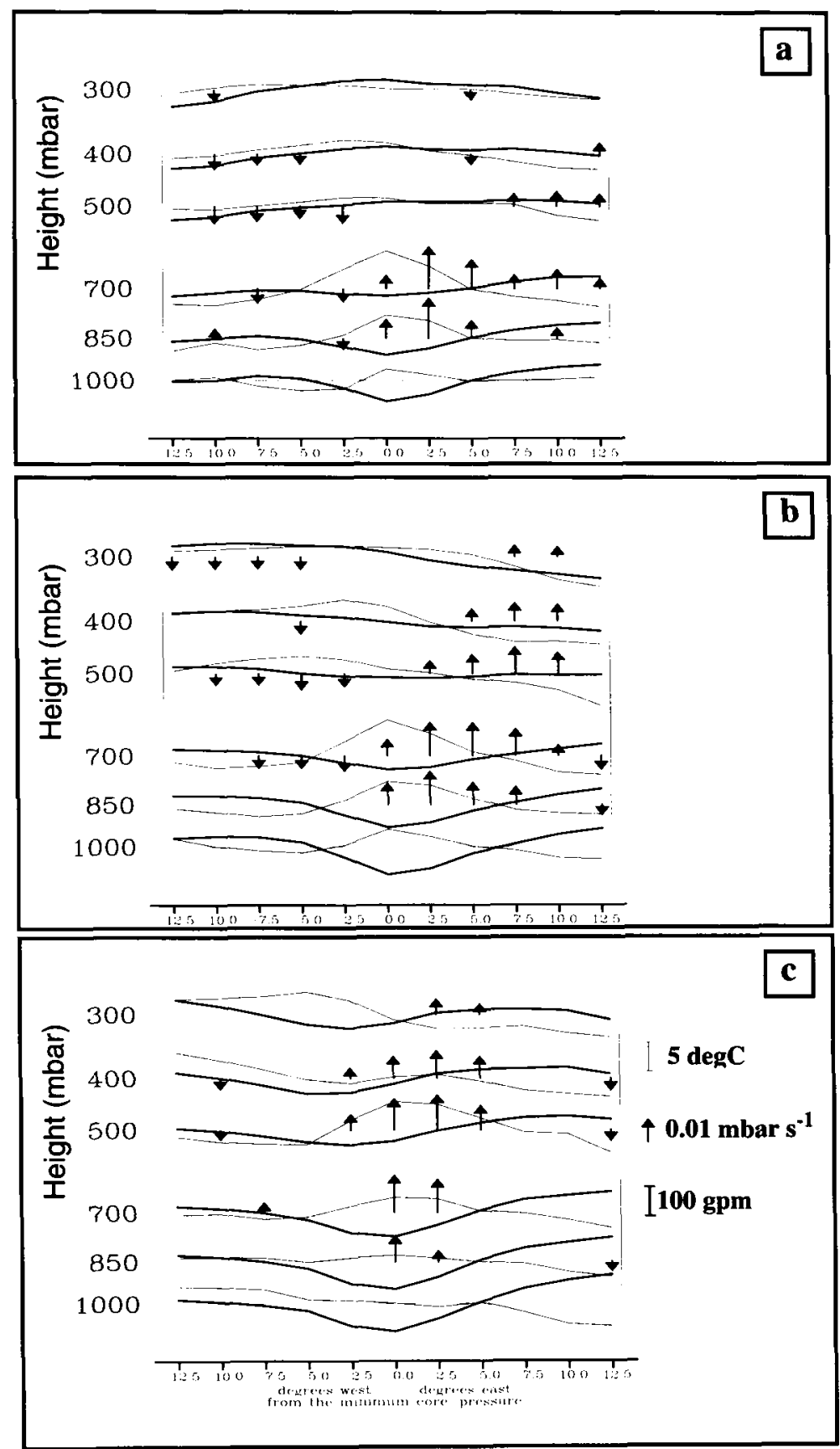

Fig. 3 Longitude-height cross-sections through cyclone Lothar for (a) 1800 GMTon 25 December 1999, (b) 0000 GMT on 26 December 1999 and (c) 0600 GMT on 26 December 1999, centred at the position of the surface core. Geopotential height (thick solid lines) and temperature anomalies (thin lines) are given, along with vertical wind speeds (arrows) at standard levels.

divergence north of the jet exit (induced by the ageostrophic winds associated with the wind speed reduction) are well known to induce rapid cyclone growth (e.g Uccellini 1990;
Baehr et al. 1999). An additional amplification of the divergence in this region is expected from the secondary jet maximum (Fig. 4) reaching from England to the Alps. When 

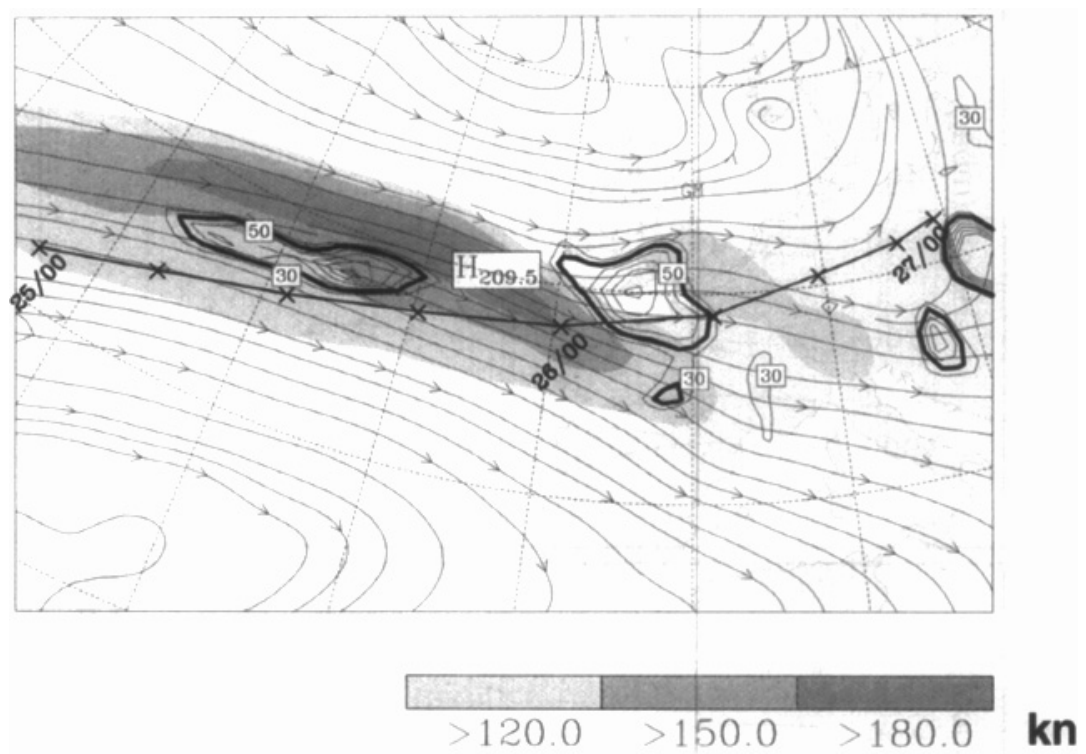

Fig. 4300 mbar analysis for $0000 \mathrm{GMT}$ on 26 December 1999. Divergence contours are drawn every $10 \times 10^{-6} \mathrm{~s}^{-1}$, starting with the $30 \times 10^{-6} \mathrm{~s}^{1}$ isopleth. The $40 \times 10^{-6} \mathrm{~s}^{-1}$ contour is bold. The shading indicates the locarion and strength of the polar jet. Streamlines, and the track and 6-hourly locations of Lothar are also shown.

Lothar reached the French coast at 0600 GMT on 26 December its central pressure had fallen to $961 \mathrm{mbar}$, rising only slowly during its further movement over France to Germany (970 mbar at $0900 \mathrm{GMT}$ ) and Poland ( 980 mbar at 1800 GMT).

In general, the extreme pressure tendencies observed at stations along Lothar's track were caused by the system's high propagation speed (about $120 \mathrm{~km} \mathrm{~h}^{-1}(65 \mathrm{kn})$ over the Atlantic and $100 \mathrm{~km} \mathrm{~h}^{-1}(54 \mathrm{kn})$ over France and Germany) and its small diameter (Fig. 1(d)). The extraordinary pressure drop of almost 26 mbar in 3 hours at Rouen (Normandy) can be understood from the additional effect of the rapid deepening of the core pressure before 0600 GMT (Fig. 5). After Lothar's passage, a pressure rise of the same order of magnitude followed ( $28 \mathrm{mbar}$ in 3 hours) before 0900 GMT. Note that similar extreme pressure tendencies were also observed at other stations in northern France and the English Channel (Le Blancq and Searson 2000). Gust wind speeds at Rouen reached $23 \mathrm{~m} \mathrm{~s}^{1}$ (45 kn) during pressure falls and $39 \mathrm{~m} \mathrm{~s}^{-1}(76 \mathrm{kn})$ during pressure rises (Fig. 5). The occurrence of maximum wind speeds shortly after the time of minimum pressure is in accordance with a time-series of 10-minute means at Karlsruhe (Germany). Widespread gales of more than $40 \mathrm{~m} \mathrm{~s}^{-1}(78 \mathrm{kn})$ hit France, Switzerland and Germany (cf. Fig. 1(b) and Table 1).

\section{Martin (25-28 December 1999)}

The next system, called Martin, followed Lothar only one day later. As mentioned before, Lothar's shallowness over the Atlantic had left the large-scale situation almost unchanged (Figs. 2(f) and 2(i)). Initially, Martin formed as a surface low on 25 December upstream of a long-wave upper-air trough over North America. The surface low moved north-eastwards along the trough's flank, which itself was slowly progressing south-eastwards over the North American east coast. A transition phase followed on 26 December. The large-scale trough over North America changed its structure. Its southerly part weakened, while farther north a short upper-air depression moved eastwards from Newfoundland. During this transition phase Martin's structure and track were ambiguous but, when it subsequently interacted with the eastwardmoving upper-air depression (0600 GMT on 27 December), it moved rapidly across the Atlan- 


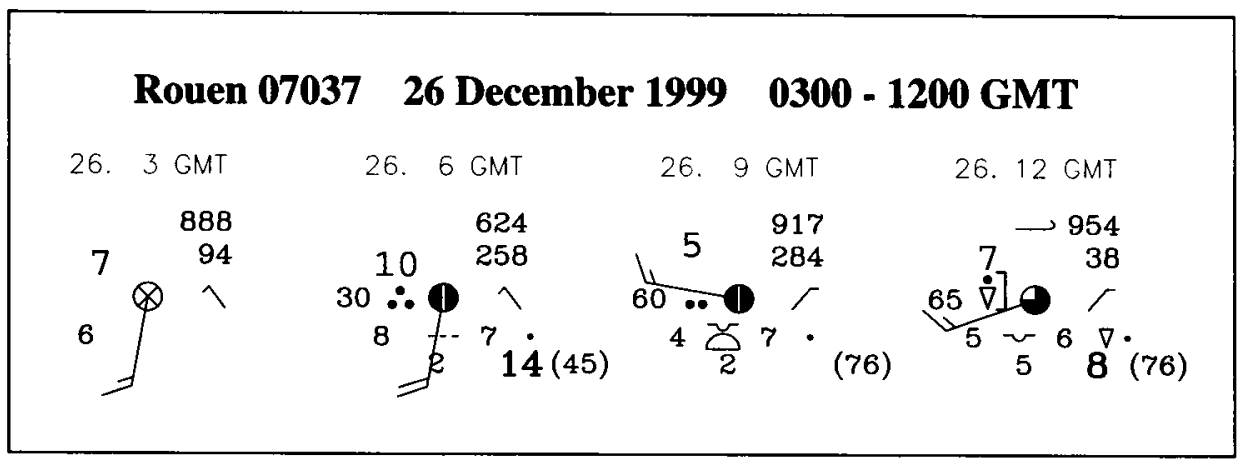

Fig. 5 3-hourly synoptic development at Rouen (France) during the passage of Lothar. Note the extreme 3-hourly pressure tendencies and the peak gust of $76 \mathrm{kn}$ that occurred after Lothar's core passed Rouen before 0600 GMT. Large figures 8 and 14 indicate rainfall $(\mathrm{mm})$ during last 6 hours.

tic. In contrast to Lothar, Martin eventually modified the large-scale airflow. Figure 2(c) shows a situation when the change over the western Atlantic is evident, while the strong gradients still prevail in the east. In fact, the polar jet was extremely intense over the latter region. At $0000 \mathrm{GMT}$ on 27 December the radiosonde at Brest (Brittany) measured a wind speed of $147 \mathrm{~m} \mathrm{~s}^{-1}(286 \mathrm{kn})$ at a height of $8138 \mathrm{~m}$ (Hontarrède 2000), about $700 \mathrm{~m}$ below the $300 \mathrm{mbar}$ level. Subsequently, Martin's central pressure fell to $965 \mathrm{mbar}$ by $1500 \mathrm{GMT}$ on 27 December, just before it entered the European continent south of Brittany (Fig. 1(c)). Violent winds first hit the French Atlantic coast (Table 1), and, to a lesser extent, northern Spain (gust wind speeds for Spain have not been available to the authors). Westerly gales of more than $36 \mathrm{~m} \mathrm{~s}^{-1}$ $(70 \mathrm{kn})$ were observed between 1500 and 2100 GMT at Bordeaux. The storm led to flooding along parts of the Atlantic coast. Subsequently, severe damage was reported along its track over southern France into the western Mediterranean.

\section{Discussion}

Local wind speeds associated with the three storms were the largest on record at several synoptic stations in the affected parts of Europe. The synoptic developments of the storms are, however, different. Both Anatol and Martin were of typical horizontal scale and modified the large-scale airflow in their wake.
In contrast, Lothar was a small-scale system (Fig. 1(d)) and did not have a strong effect on the large-scale flow over the Atlantic. Its peculiarity was being 'capped' over the Atlantic. Another difference is the tracks of the systems. Lothar and Martin crossed the Atlantic at a rather southerly position, while Anatol developed at higher latitudes (about $54^{\circ} \mathrm{N}$, Fig. $2(\mathrm{a})$ ).

The storms revealed common characteristics regarding the large-scale conditions leading to their development. One aspect was the existence of a large band of very high baroclinicity (Figs. 2(g), (h) and (i)) along the path of the cyclones over the Atlantic, which extended to the European continent; another was the existence of an airmass with high $\theta_{e}$ south of the cyclone track (Figs. 2(d), (e) and (f)) which could enhance cyclone growth, in particular due to the release of latent heat.

The extraordinariness of the large-scale conditions associated with the three storms was quantified from the exceedance by several variables of the 95th and 99th percentiles for the reference period 1957/58-1997/98. Figures $2(\mathrm{~g})$, (h) and (i) indicate that for all three storms baroclinicity clearly exceeded the 95 th percentile of the respective values for the winters (December, January, February) in the reference period. The two late-December storms, Lothar and Martin, were even associated with a zonally elongated band of 99 th percentile exceedance over the Atlantic. For computing the percentiles of $\theta_{\mathrm{e}}$, its strong annual cycle has to be taken into account. Thus, for each storm 
a sample containing all 6-hourly values from the respective 40 weeks (centred on the storm date) in the period 1958-97 was used. The $\theta_{e}$ percentiles also reveal rather large positive anomalies for each of the three cyclones, with the source of the moist air apparently lying in the Sargasso Sea (Figs. 2(d), (e) and (f)). Exceedance of the 95th or 99 th percentiles is, however, found only at a few grid points south of the track.

In order to put the December 1999 storms into a historical context, we chose three other intense storms that produced large damage over Europe (e.g. Lamb 1991). Their tracks and the associated anomalies in baroclinicity and $\theta_{c}$ were computed. The track of the cyclone that caused major damage in Denmark on 23 November 1981 is shown in Figs. 6(a) and $6(\mathrm{~d})$. As we found for the recent storms, the large-scale fields for the 1981 storm reveal a zone of extraordinarily high baroclinicity located between Iceland and the British Isles (Fig. 6(a)), i.e. upstream of the region of largest wind speeds. High local $\theta_{\mathrm{c}}$ values also occurred in conjunction with the storm. They ranked as extraordinary over a rather large area around the British Isles (Fig. 6(d)).

The second storm considered for comparison hit north-western France and England on 15/16 October 1987. The corresponding cyclone track was at a very southerly position before the low reached Europe (Fig. 6(b)). Again, a band of very high baroclinicity was present over the eastern North Atlantic. The track curved northwards when reaching the European continent. Unusually high $\theta_{\mathrm{e}}$ values observed over a fairly large area (Fig. 6(e)) led to a dominance of latent heat release over the dry baroclinic instability process during the rapid intensification of the system (Shutts 1990). According to Fig. 6(b), high baroclinicity was not observed over south-west England where the storm reached its maximum intensity.

The third storm considered is one of the series of European storms in February 1990. The damage occurred mainly in Germany and Switzerland on 1 March 1990. Like the other storms, this cyclone is associated with a band of high baroclinicity near the track of its core. However, local values do not exceed the 99th percentile. There is also an area of enhanced $\theta_{\text {e }}$, but only a few local values are rated as extreme.

Summing up, we find that the existence of bands of extremely high baroclinicity and high values of $\theta_{e}$ are typical for European storm events (see also Busch et al. 1998). In detail, there are differences in how extreme these bands are, differences in their relative importance, and in their location. The anomalies are, however, always found over the eastern North Atlantic, close to or extending into the European continent.

With respect to the scientific and public discussion on anthropogenic climate change one should emphasise that the occurrence of the storms cannot be taken as evidence for an enhanced greenhouse gas effect. Firstly, such an attempt would be inappropriate from a statistical point of view (see Frei and Schär 2001). Secondly, only the first of the three storms, Anatol, seems to fit the greenhouse gas signal recently described by Knippertz et al. (2000). Considering a particular greenhouse gas forcing experiment they found a rising number of extreme wind events in the northern parts of Europe, associated with an increasing number of deep lows and enhanced mean upper-air baroclinicity over the north-eastern Atlantic. In contrast, the model simulated a decrease in the number of extreme wind events and in baroclinicity for the regions where Lothar and Martin occurred. It should also be mentioned that low-resolution climate models are unable to produce small-scale cyclones and their associated wind fields.

\section{Conclusions}

Extreme winds were produced by the three cyclones that hit Europe (Denmark, northern France to southern Germany and Switzerland, southern France) in December 1999. For some of the recording stations, the observed gust wind speeds were of record-breaking intensity. For each event, there was a band of extremely high baroclinicity near the cyclone track over the eastern North Atlantic and extending partly into Europe. High $\theta_{\mathrm{e}}$ values were observed south of the track. These largescale characteristics are common to European 

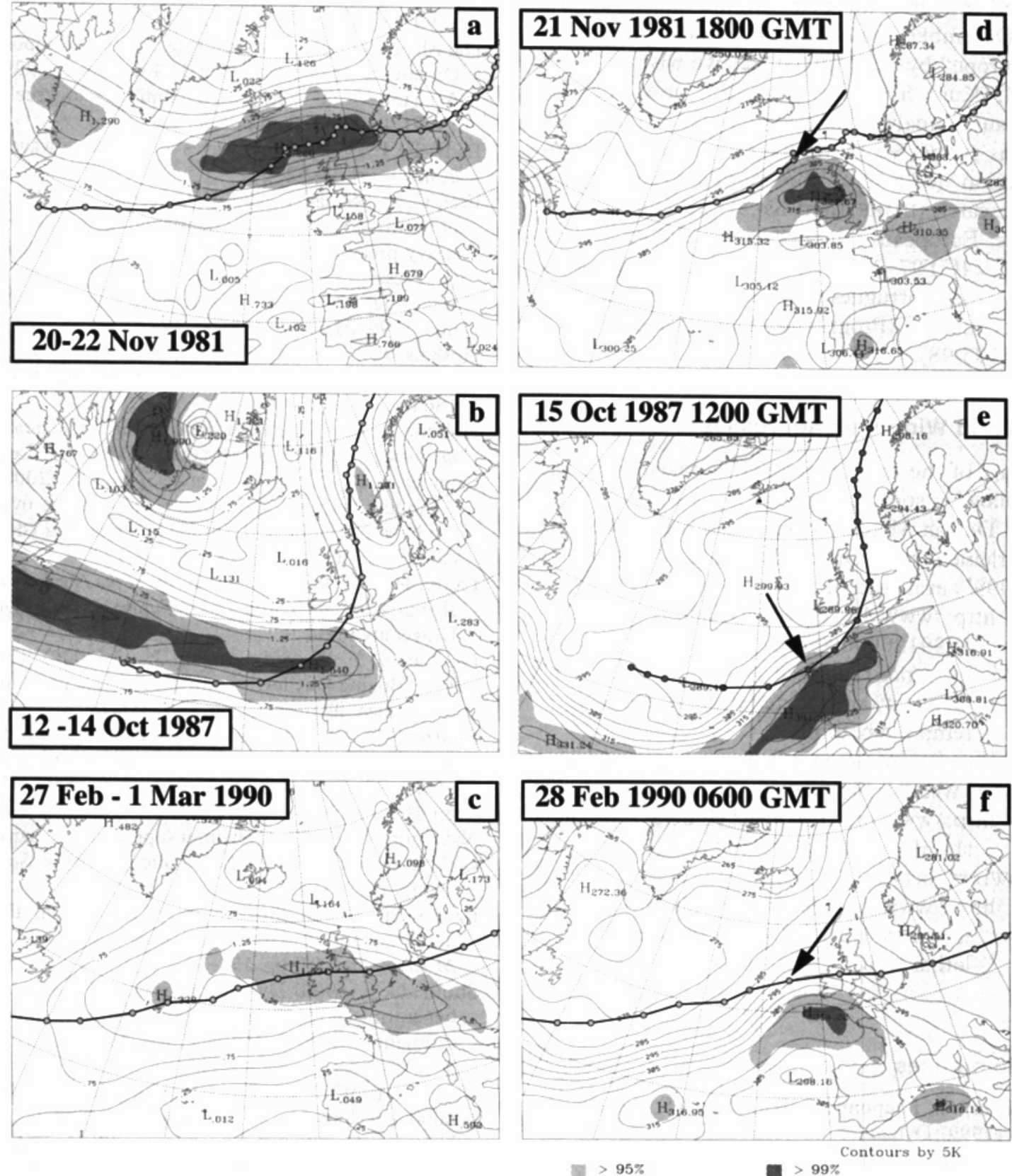

Fig. 6 Fields of maximum Eady growth rate (per day) and equivalent potential temperature (contour interval $5 \mathrm{~K}$ ) at 850 mbar for three historic European storm events. For more details see caption to Fig. 2.

storm events, though the details of the synoptic development are rather different.

\section{Acknowledgements}

A number of station data were taken from the
Berliner Wetterkarte issued by the Berlin Meteorological Institute. The ECMWF analysis was obtained with the permission of the German Weather Service. NCEP reanalysis data were provided by the German Climate Computing Centre. Information on damage 
and casualties was taken from a bulletin on the "December gales Lothar and Martin in Europe" by the Munich Re. We wish to thank $M$. Kurz from the DWD for providing the manual analysis map in Fig. 1(d). This work was supported by the German Science Foundation (SFB419), the German Ministry of Research (BMBF grant No. 01 LA9861/5), and the European Union (project STOEC, grant ENV4CT97-0499). J. G. Pinto is supported by the Portuguese Office for Science and Technology (Program PRAXIS XXI, grant BD/ 15775/98).

\section{World Wide Web addresses}

Part of the data mentioned is taken from the following sources:

Danish Meteorological Institute's "Rapport Orkanen over Danmark den 3.-4 december 1999", available at:

http://www.dmi.dk/vejr/aktuelt/ 199912090000/orkan.pdf

Météo-France reports at:

http://www.cnrm.meteo.fr/dbfastex/recyf_ temp/index.html

http://www.meteo.fr/la_une/tempetes.html

Swiss Weather Service report at:

http://www.meteoschweiz.ch/de/a_z/lothar. shtml

DWD reports at:

http://www.dwd.de/research/klis/produkte/ monitoring/orkan 19991226/orkanlothar.htm

\section{References}

Baehr, C., Pouponneau, B., Ayrault, F. and Joly, A. (1999) Dynamical characterization of the FASTEX cyclogenesis cases. Q. F. R. Meteorol. Soc, 125, pp. 3469-3494

Busch, U., Beckmann, B. R. and Roth, R. (1998) Study of storm weather situations in observation and ECHAM3/T42 model simulation. Tellus, A50, pp. $411 \cdots 423$

Bolton, D. (1980) The computation of equivalent potential temperature. Mon. Wea. Rev., 108, pp. 1046-1053

Christoph, M., Ulbrich, U. and Speth, P. (1997) Midwinter suppression of Northern Hemisphere storm track activity in the real atmosphere and in
GCM experiments. F. Atmos. Sci., 54, pp. 15891599

Danish Meteorological Institute (2000) Rapport Orkanen over Danmark den 3.-4 december 1999. Available at http:/www.dmi.dk/vejr/aktuelt/ 199912090000/orkan.pdf

Eady, E. T. (1949) Long waves and cyclone waves. Tellus, 1, pp. 33-52

Frei, C. and Schär, C. (2001) Detection probability of trends in rare events: Theory and application to heavy precipitation in the Alpine region. 7 . Clim. (In Press)

Hontarrède, M. (2000) Les tempétes jumelles de noël 1999. Met Mar, 187, pp. 3-5

Hoskins, B. J. and Valdes, P. J. (1990) On the existence of storm-tracks. F. Atmos. Sci., 47, pp. 1854 1864

Holton, J. R. (1992) An introduction to dynamic meteorology, 3rd edition. Academic Press, London

Knippertz, P., Ulbrich, U. and Speth, P. (2000) Changing cyclones and surface wind speeds over the North-Atlantic and Europe in a transient GHG experiment. Clim. Res., 15, pp. 109-122

Lamb, H. H. (1991) Historic storms of the North Sea, British Isles and northwestern Europe. Cambridge University Press

Le Blancq, F. W. and Searson, J. A. (2000) The 1999 Boxing Day low - some remarkable pressure tendencies. Weather, 55, pp. 250-251

Lindzen, R. S. and Farrell, B. (1980) A simple approximate result for the maximum growth rate of baroclinic instabilities. f. Atmos. Sci., 37, pp. 1648-1654

Nakamura, H. (1992) Midwinter suppression of baroclinic wave activity in the Pacific. 7 . Atmos. Sci, 49, pp. 1629-1642

Petterssen, S. and Smebyc, S. J. (1971) On the development of extratropical cyclones. $Q$. $7 . R$. Meteorol. Soc., 97, pp. 457-482

Shutts, G. J. (1990) Dynamical aspects of the October storm, 1987: A study of a successful fine-mesh simulation. Q. F. R. Meteorol. Soc., 116, pp. 13151347

Uccellini, L. W. (1990) Processes contributing to the rapid development of extratropical cyclones. In: Newton, C. W. and Holopainen, E. O. (Eds.) Extratropical cyclones, the Eric Paimen memorial volume, American Meteorological Society, Boston, pp. 81-105

Correspondence to: Dr U. Ulbrich, Institut für Geophysik und Meteorologie der Universität zu Köln, 50923 Köln, Germany. e-mail: ulbrich $(a)$ meteo.uni-koeln.de 